\title{
Comparability of dominance indices in captive pigtail macaques (Macaca nemestrina)
}

\author{
LINDA S. RAYOR \\ University of Kansas, Lawrence, Kansas 66045 \\ and \\ DAVID CHISZAR \\ University of Colorado, Boulder, Colorado 80309
}

\begin{abstract}
Frequencies of five agonistic behaviors were recorded in a captive group $(n=11)$ of pigtail macaques (Macaca nemestrina) at the Chicago Zoological Park (Brookfield Zoo). The data were used to construct rank orders according to three procedures. One of the procedures considered dyadic factors in assigning ranks, the other procedures did not. The first procedure was found to be the most reliable and to predict the results of the second and third procedures better than they predicted themselves. Furthermore, inclusion of data from infant monkeys produced serious distortions in the two nondyadic procedures, but not in the dyadic one.
\end{abstract}

That social dominance hierarchies exist and can be used as valuable descriptive tools in understanding primate social organization is agreed upon by many researchers (Alvarez, 1975; Candland, Dresdale, Leiphart, Bryan, Johnson, \& Nazar, 1973; Deag, 1977; Hausfater, 1975; Richards, 1974). The distribution of freely occurring agonistic behavior among individuals is generally accepted as the most useful approach to obtaining valid measures of social dominance (see Deag's, 1977, review). However, the frequency and direction of these agonistic interactions can be analyzed in different ways. Operationally distinct measures of dominance often produce quite different views of hierarchical relationships between animals in the same group (Alvarez, 1975; Syme, 1974). For this reason, it is necessary to assess the comparability of dominance indices in order to determine whether operationally distinct measures tap common or different dimensions. The present paper reports such an assessment for five behavioral measures in pigtail macaques.

\section{METHOD}

\section{Subjects}

Eleven animals, comprising a well established family group at the Chicago Zoological Park (Brookfield Zoo), served as subjects. The five males were aged $192+, 59,16,3$, and 1 months, respectively; the six females were aged $192+, 89,71,46,15$, and 6 months, respectively. The oldest adult female was the mother of most (six) of the younger animals; the next three females (all daughters of the oldest one) each had one offspring, bringing

Financial support for this project was provided by the Brookfield Zoo and the M. M. Schmidt Foundation. We thank Dr. B. Beck for advice and guidance during the conduct of this project. Requests for reprints should be addressed to L. Rayor, Department of Systematics and Ecology, University of Kansas, Lawrence, Kansas 66045. the total group size to 11 . The oldest adult male was the father of all offspring.

\section{Maintenance Conditions}

The group was housed in a $356 \times 183 \times 239 \mathrm{~cm}$ indoor cage connected to a $356 \times 317.5 \times 183 \mathrm{~cm}$ outdoor cage. Three walls of each cage were constructed of gunite, the floors of terrazzo, and the ceiling and fronts of metal bars. The cages contained shelves and a simulated tree branch. The animals' diet consisted of a daily supply of fruits and vegetables supplemented by commercial monkey chow. Water was continuously available.

\section{Procedure}

A total of $50 \mathrm{~h}$ of observation was made between 0800-1030 and 1400-1530 on 15 days between June 12 and 29, 1976. Morning observations were made while animals were in the outside cage before visitors arrived at the zoo. Afternoon observations were conducted inside, during which the animals were fed and zoo visitors were present. Each animal was in view of the observer at all times. Using an ad-lib sampling procedure, the observer recorded the initiators and recipients of five conspicuous, socially meaningful, and previously defined behaviors (Kaufman \& Rosenblum, 1966): (1) low-intensity fight (LIF-one animal grabs, hits, pushes, pulls, or manually restrains another), (2) threat ( $\mathrm{T}$-one animal thrusts head forward with brows retracted, mouth open, and ears flattened against head), (3) high-intensity fight (HIF-like LIF, but also involves lunging, chasing, and/or biting), (4) grimace (G-mouth slightly opened, lips retracted, and incisors exposed), (5) nonsexual present (NSP-hindquarters oriented toward another animal, tail elevated and averted, limbs extended, and the initiator looking back toward recipient). NSP was not scored if the initiator was a female in estrus. The first three behaviors are overt agressive actions and are considered to be expressions of dominance (depending upon their relative frequencies); G and NSP are considered to be submissive responses (Kaufman \& Rosenblum, 1966). Accordingly, in addition to analyzing each response type separately, two composite variables were constructed and analyzed. The first composite was formed by adding the frequencies of LIF, T, and HIF for each subject; the second was formed by adding the frequencies of G and NSP. The first composite is called overall dominance score (ODS), the second is called overall submission score (OSS). Therefore, 
a total of seven response scales were available for use in constructing dominance hierarchies.

\section{Statistical Analysis}

Hierarchies or dominance ranks were formed from each of the seven scales in three fundamentally different ways. The first procedure involved assigning an animal a rank on the basis of the total frequency with which that animal initiated the response type under consideration. Seven rankings are created in this manner, one for each' response scale. The second procedure involved assigning an animal a rank on the basis of the total frequency with which that animal received the response under consideration. Seven more rank orders are thereby created. Notice that these two procedures ignore dyadic factors; no attention is given in the first case to the recipients of the responses or in the second case to the initiators of the responses. Following the terminology of Alvarez (1975), these rankings will be called performance rank orders (PROs). Specifically, PROs based on initiation of responses will be called PRO-Is, and those based on receipt of responses will be called PRO-Rs.

The third procedure for forming ranks is more complex and considers dyadic factors. This was done by constructing matrices containing the frequency with which all animals initiated and received each kind of response. A separate matrix was constructed for each of the seven response scales. Next, the rows and columns of each matrix were rotated until the sum of frequencies above the principal diagonal was maximized. The resulting arrangement of subjects was then taken to be a directional rank order (DRO; Alvarez, 1975). Table 1 illustrates all three kinds of rank orders for ODS.

A total of 21 rank orders were generated by application of the three methods to the seven response scales. The major question is the extent to which these operationally distinct rankings agree (correlate) with each other. This involves the calculation of 210 Spearman rank-correlation coefficients (SRC). The SRCs can be broken into four subquestions, each of which is treated separately in the Results and Discussion section.

Three monkeys in our sample were infants, and they neither initiated nor received many responses of any type. This presents a difficulty, especially when PRO-Rs are constructed. Namely, the infants tend to be assigned high ranks because they, just as the adult male, received few LIFs, Ts, or HIFs. Accordingly, all 210 SRCs were computed twice, once with the infants included in the sample and once with them removed.

\section{RESULTS AND DISCUSSION}

\section{Correlations Among DROs}

All DROs are significantly and strongly correlated with each other. This was true for SRCs based on $n=11$ as well as for SRCs based on $n=8$ (see Table 2). We interpret high SRCs among rank orders computed by the same procedure to be measures of the procedure's reliability. Hence, the DRO method is judged to be extremely reliable.

Rank orders based on LIF, T, HIF, and ODS were positively related with each other, as were ranks based on G, NSP, and OSS. However, all of the former were negatively correlated with the latter. This is exactly what would be expected on the basis of the interpretations given to the response types by Kaufman and Rosenblum (1966), and this is the basis for the third column in each of the cells of Table 2 (that is, SRCs among rank orders derived from LIF, T, HIF, and ODS are expected to be positive, as are SRCs among G, NSP, and OSS, whereas SRCs between these two sets are expected to be negative).

\section{Correlations Among PRO-Is}

Although the number of significant SRCs among PRO-Is exceeds chance expectations, this procedure does not give rise to as many significant coefficients as the DRO procedure. Dropping the infants from the sample did not improve the significance of the

Table 1

Overall Dominance Scores: The Frequency and Directionality of High-Intensity Fights, Low-Intensity Fights, and Threats Combined

\begin{tabular}{|c|c|c|c|c|c|c|c|c|c|c|c|c|c|c|}
\hline \multirow[b]{2}{*}{ Initiator } & \multicolumn{12}{|c|}{ Recipient } & \multicolumn{2}{|c|}{ Ranks } \\
\hline & M1 & $\mathrm{F} 1$ & F3 & F4 & $\mathrm{F} 2$ & M2 & M4 & F5 & F6 & M5 & M6 & fi & DRO & PRO-I \\
\hline M1 & & 27 & 50 & 11 & 14 & 29 & 27 & 34 & 8 & 0 & 0 & 200 & 1 & 1 \\
\hline F1 & 2 & & 19 & 19 & 8 & 19 & 13 & 38 & 4 & 3 & 0 & 125 & 2 & 2 \\
\hline F3 & 3 & 0 & & 14 & 8 & 23 & 21 & 5 & 10 & 2 & 0 & 86 & 3 & 5 \\
\hline F4 & 0 & 0 & 0 & & 12 & 25 & 29 & 36 & 3 & 2 & 0 & 107 & 4 & 4 \\
\hline F2 & 0 & 1 & 3 & 1 & & 27 & 30 & 47 & 2 & 1 & 0 & 112 & 5 & 3 \\
\hline M2 & 8 & 0 & 2 & 12 & 8 & & 18 & 11 & 0 & 0 & 0 & 59 & 6 & 6 \\
\hline M4 & 8 & 1 & 1 & 2 & 0 & 1 & & 9 & 0 & 1 & 0 & 23 & 7 & 7 \\
\hline F5 & 1 & 0 & 0 & 1 & 2 & 2 & 9 & & 3 & 0 & 0 & 18 & 8 & 8 \\
\hline F6 & 0 & 0 & 1 & 0 & 0 & 0 & 0 & 0 & & 0 & 0 & 1 & 9 & 10 \\
\hline M5 & 0 & 0 & 1 & 1 & 0 & 0 & 0 & 0 & 1 & & 0 & 3 & 10 & 9 \\
\hline M6 & 0 & 0 & 0 & 0 & 0 & 0 & 0 & 0 & 0 & 0 & & 0 & 11 & 11 \\
\hline fr & 22 & 29 & 77 & 61 & 52 & 126 & 147 & 180 & 31 & 9 & 0 & 734 & & \\
\hline PRO-R & 3 & 4 & 8 & 7 & 6 & 9 & 10 & 11 & 5 & 2 & 1 & & & \\
\hline
\end{tabular}

Note-Ranks were determined in three ways. First, PRO-I was obtained by inspecting overall frequency of initiation of responses (fi).

Second, PRO-R was obtained by inspecting overall frequency of receipt of response (fr). Third, DRO was determined by positioning the subjects in the table so that a minimal number of interactions occurred below the diagonal; the arrangement of subjects along either dimension of the table is then taken as the DRO (see Alvarez, 1975, for details and interpretation). 
Table 2

Measures Summarizing SRC Analyses

\begin{tabular}{|c|c|c|c|c|c|c|c|c|c|c|c|c|c|c|c|}
\hline & \multicolumn{5}{|c|}{ DRO } & \multicolumn{5}{|c|}{ PRO-I } & \multicolumn{5}{|c|}{ PRO-R } \\
\hline & $\mathbf{N}$ & SRCs & A & B & $\mathrm{C}$ & $\mathbf{N}$ & SRCs & A & B & C & $\mathbf{N}$ & SRCs & A & B & $\mathrm{C}$ \\
\hline DRO & $\begin{array}{r}11 \\
8\end{array}$ & $\begin{array}{l}21 \\
21\end{array}$ & $\begin{array}{l}100^{*} \\
100^{*}\end{array}$ & $\begin{array}{l}100^{*} \\
100^{*}\end{array}$ & $\begin{array}{l}.9599 \\
.9076\end{array}$ & $\begin{array}{r}11 \\
8\end{array}$ & $\begin{array}{l}49 \\
49\end{array}$ & $\begin{array}{l}57 \\
86^{*}\end{array}$ & $\begin{array}{l}71^{*} \\
57^{*}\end{array}$ & $\begin{array}{l}.6092 \\
.4827\end{array}$ & $\begin{array}{r}11 \\
8\end{array}$ & $\begin{array}{l}49 \\
49\end{array}$ & $\begin{array}{c}55 \\
100^{*}\end{array}$ & $\begin{array}{l}43^{*} \\
69^{*}\end{array}$ & $\begin{array}{l}.3136 \\
.6390\end{array}$ \\
\hline PRO-I & & & & & & $\begin{array}{r}11 \\
8\end{array}$ & $\begin{array}{l}21 \\
21\end{array}$ & $\begin{array}{l}43 \\
81^{*}\end{array}$ & $\begin{array}{l}43^{*} \\
33^{*}\end{array}$ & $\begin{array}{l}.4570 \\
.3524\end{array}$ & $\begin{array}{r}11 \\
8\end{array}$ & $\begin{array}{l}49 \\
49\end{array}$ & $\begin{array}{l}57 \\
84^{*}\end{array}$ & $\begin{array}{l}37 * \\
41^{*}\end{array}$ & $\begin{array}{l}.2789 \\
.4232\end{array}$ \\
\hline PRO-R & & & & & & & & & & & $\begin{array}{r}11 \\
8\end{array}$ & $\begin{array}{l}21 \\
21\end{array}$ & $\begin{array}{c}62 \\
100^{*}\end{array}$ & $\begin{array}{l}43^{*} \\
43^{*}\end{array}$ & $\begin{array}{l}.3174 \\
.4783\end{array}$ \\
\hline
\end{tabular}

Note-N = number of monkeys in sample; $S R C s=$ number of SRCs calculated; $A=$ percent $S R C s$ in expected direction; $B=$ percent $S R C s$ significant; $C=$ averaged squared SRC. Cells are numbered from left to right starting with the first two-line group (i.e., DRO by $D R O)$. Measure A reflects the correctness of our interpretations of the responses. Measures $B$ and $C$ reflect the "connectedness" among (Cells 1, 4, and 6) and between (Cells 2, 3, and 5) rank orders constructed according to three different procedures.

*Significantly greater than chance by chi-square test. Chance expectation for Measure A was taken to be 50\%; chance expectation for Measure B was taken to be $5 \%$

SRCs, but it did cause more SCRs, to conform to directional expectations. In general, PRO-Is are not as strongly intercorrelated and, hence, not as reliable as DROS.

\section{Correlations Among PRO-Rs}

The pattern of SRCs among PRO-Rs is comparable to the pattern for PRO-Is. Both procedures are strongly distorted by inclusion of infants who initiated and received few submissive and aggressive responses. Both procedures are far less reliable than DROs.

\section{Correlations Between DROs, PRO-Is, and PRO-Rs}

The most conspicuous finding in this part of our analysis is that DROs predict PRO-Is and PRO-Rs as well as or better than these latter procedures predict themselves (compare Cells 2 and 3 of Table 2 with Cells 4 and 6, respectively) or each other (Cell 5, Table 2). Accordingly, we agree with other workers (Deag, 1977; Kawai, 1958; Loy, 1976), who have suggested that DROs are the most reliable indicies of dominance ranks and should therefore be preferred over indicies based on nondyadic frequency assessments.

Of equal importance is the fact that inclusion of infants does not influence DROs, whereas serious distortions appear in PROs. In every analysis involving PRO-Is and PRO-Rs, directionality of SRCs was subsequently improved by eliminating infants. Yet, even these adjusted SRCs did not attain the magnitudes seen for DROs, again indicating the inherently greater stability of the latter method.

\section{REFERENCES}

Alvarez, F. Social hierarchy under different criteria in groups of squirrel monkeys, Saimiri sciureus. Primates, 1975, 16, 437-455.

Candland, D., Dresdale, L., Leiphart, J., Bryan, D., Johnson, C., \& NAzAR, B. Social structure of the squirrel monkey (Saimiri sciureus, Iquitos): Relationships among behavior, heartrate, and physical distance. Folia Primatologica, 1973, 20, 211-240.

DeAg, J. M. Aggression and submission in monkey societies. Animal Behaviour, 1977, 25, 465-474.

Hausfater, G. Dominance and reproduction in Baboons (Papio cynocephalus). In H. Kuhn, W. Luckett, C. Noback, A. Schultz, D. Starck, \& F. Szalay (Eds.), Contributions to Primatology (Vol. 7). Basel: S. Karger, 1975.

Kaufman, I., \& Rosenblum, L. A behavioral taxonomy for Macaca nemestrina and Macaca radiata based on longitudinal observation of family groups in the laboratory. Primates, 1966, 7, 205-258.

KAWAI, M. On the rank system in a natural troop of Japanese monkeys (I): Basic rank and dependent rank. Primates, 1958, 1, 111-130.

LoY, J. The descent of dominance in Macaca: Insights into the structure of human societies. In R. Tuttle (Ed.), Socioecology and psychology of primates. Chicago: Mouton, 1976.

RichaRDS, S. M. The concept of dominance and methods of assessment. Animal Behaviour, 1974, 22, 914-930.

SYME, G. Competitive orders as measures of social dominance. Animal Behaviour, 1974, 22, 931-940.

(Received for publication September 12, 1978.) 